\title{
CLVII. THE PHOSPHORUS OF CASEINOGEN.
}

\section{ISOLATION OF A PHOSPHORUS-CONTAINING PEPTONE FROM TRYPTIC DIGESTS OF CASEINOGEN.}

\author{
By CLAUDE RIMINGTON. \\ (Benn W. Levy Student, Research Scholar of Emmanuel College, Cambridge.) \\ From the Biochemical Laboratory, Cambridge.
}

(Received August 29th, 192\%.)

THE work described in this paper was commenced in 1924, and a preliminary report issued in the following year [Rimington and Kay, 1925], in which it was stated that from tryptic digests of caseinogen a preparation had been obtained containing amino-acids in association with phosphoric acid, and representing approximately $10 \%$ of the organic phosphorus of the original digest.

Since that time, experimental work has been directed along two main lines of approach. In the first place an investigation of the behaviour of caseinogen towards various proteolytic enzymes, phosphatases, acids and alkalis was made [Rimington and Kay, 1926; Rimington, 1927, 1], from which it was possible to draw certain conclusions relative to the state of combination of phosphorus in the caseinogen molecule. The linkage involved appears to be of the ester type, phosphoric acid being united to some hydroxyl-containing constituents of the protein molecule, most probably hydroxyamino-acids. A study of artificially phosphorised proteins [Rimington, 1927, 1] afforded additional evidence in support of this view.

At the same time experiments were being continued having as their object the isolation in a pure state of the phosphorus-containing substance present in tryptic digests of caseinogen. This has now been accomplished, and it is with this isolation that the present paper is concerned.

\section{Isolation of a PHOSPHORUS-CONTAINING PEPTONE.}

The liberation from caseinogen, during the action of trypsin, of an acidsoluble, organic substance containing all the phosphorus of the protein has been noted by Biffi [1898], Plimmer and Bayliss [1906] and others, but neither Dr Kay nor myself was aware, when these experiments were begun, that any serious attempt had been made to isolate this substance. Our attention has since been called by Posternak [1927] to a Swiss patent taken out by 
the Society of Chemical Industry in Basle [1923] in which the separation of a preparation containing organically combined phosphorus from caseinogen digests is described. A discussion of this and of Posternak's later work will be found below.

In an earlier communication it was shown that the liberation of the soluble organic substance by trypsin occurs with great rapidity, the subsequent splitting off of phosphoric acid taking place at a much slower rate. Isolation at the period when the soluble organic phosphorus was at a maximum did not however yield the best results as the quantity of peptide material present in these early stages was relatively great. By trial it was found that the best time to commence operations was 38-40 hours after the addition of trypsin. In illustration of the process, the details of an actual preparation are given.

$1 \mathrm{~kg}$. of caseinogen was digested with $500 \mathrm{cc}$. strained extract of pancreas in the presence of toluene for 38 hours at $37^{\circ}$ and a $p_{\mathrm{H}}$ of 8.4 to $8 \cdot 6$, the total volume of liquid being $11 \mathrm{l}$. Glacial acetic acid was then added to bring the $p_{\text {H }}$ to 4.5 and the whole filtered through fine linen. The filtrate $(11.11$.) contained $4 \cdot 2 \mathrm{~g}$. organic phosphorus.

1.8 l. of saturated lead acetate and $700 \mathrm{cc}$. of ammonia were then added in the order mentioned, the supernatant liquid removed and the precipitate filtered off. After repeated washing with water, it was suspended in water and decomposed by hydrogen sulphide. The filtrate, freed from hydrogen sulphide by a stream of air, was rendered alkaline with ammonia and magnesia mixture added with vigorous stirring. Precipitated magnesium ammonium phosphate was filtered off.

The filtrate was now adjusted to $p_{\mathrm{H}} 3.8$ by means of acetic acid and hot saturated uranium acetate solution added until no further precipitation occurred. The precipitate was filtered off, washed thoroughly, and suspended in water, to this suspension sufficient $10 \%$ sulphuric acid being added to effect complete solution. Well cooled $40 \%$ sodium hydroxide was then added with vigorous stirring until all the uranium was precipitated. This was then filtered off by suction into flasks containing a little acetic acid in order to neutralise the filtrate immediately, since the substances sought are unstable in alkaline solution. No other method of removing the uranium was found to be practicable, but it was possible to carry out the whole of the above process, from the addition of the sodium hydroxide to the collection of the filtrates, within 5 minutes.

The uranium-free filtrates were combined, the resulting liquid having a slightly acid reaction. It possessed an $\mathrm{N} / \mathrm{P}$ ratio of approximately $5 / 1$, gave a strong biuret reaction (red) but no Millon and no glyoxylic reactions. A solution of phosphotungstic acid produced no precipitate.

The insoluble copper salt was next prepared by the addition to the solution of sufficient saturated copper acetate to produce complete precipitation. About 2 l. of copper acetate solution were required, the total volume amounting to 51 . 
This precipitate was filtered off, washed and dried over sulphuric acid in vacuo (copper precipitate I): weight $55.5 \mathrm{~g}$; t total phosphorus $4.81 \%$; total nitrogen $7.50 \%$; ratio $\mathrm{N} / \mathrm{P}=3.45$ : yield $65 \%$ of the organic phosphorus of the digest. For this stage the above yield is typical, although on one occasion as much as $74 \%$ of the original organic phosphorus of the digest was obtained.

This substance, whose ratio $\mathrm{N} / \mathrm{P}$ did not differ greatly from one of the preparations described by Posternak [1927], was not yet pure as was shown by fractional precipitation with copper acetate in the following manner.

15 g. copper precipitate $I, N / P=3 \cdot 45$, were suspended in water and decomposed by hydrogen sulphide. After filtration, using well washed "fuller's earth ${ }^{1}$ " to remove the last traces of colloidal copper sulphide, the liquid was again treated with saturated copper acetate solution, $280 \mathrm{cc}$. being required to produce complete precipitation. The resulting precipitate (copper precipitate II) was separated, washed and decomposed as before. The solution was now treated with copper acetate in successive small quantities, the precipitates produced at each addition being separately removed. A fractionation was thus achieved, the four precipitates, referred to as copper precipitate III $A, B, C$ and $D$ respectively, being analysed for phosphorus and nitrogen with the following results.

Table I.

$\begin{array}{ccccc}\text { Cu ppt. III } & \begin{array}{c}\text { Weight } \\ \text { g. }\end{array} & \begin{array}{c}\text { Phosphorus } \\ \%\end{array} & \begin{array}{c}\text { Nitrogen } \\ \%\end{array} & \text { N/P } \\ A & 1.72 & 6.34 & 7 \cdot 44 & \frac{2 \cdot 60}{1} \\ B & 5 \cdot 50 & 5.50 & 7.32 & \frac{2.95}{1} \\ C & 2.53 & 5.32 & 7 \cdot 43 & \frac{3.09}{1} \\ D & 2 \cdot 22 & 5.09 & 7 \cdot 30 & \frac{3 \cdot 18}{1} \\ \text { Total recovered } & \overline{11.97} & & & \end{array}$

It is evident that the greater part of the material, amounting to $67 \%$ of the total quantity, comes down in the middle fractions $(B$ and $C)$ with a ratio $\mathrm{N} / \mathrm{P}=3$. Repeated reprecipitation and fractionation of this material failed to alter its $\mathrm{N} / \mathrm{P}$ ratio. It was therefore considered to be homogeneous and analysed ${ }^{2}$ with the following result, from which the empirical formula $\left(\mathrm{C}_{37} \mathrm{H}_{53} \mathrm{O}_{33} \mathrm{~N}_{9} \mathrm{P}_{3}\right) \mathrm{Cu}_{4 \cdot 5}$ was deduced. It contained no sulphur.

$\begin{array}{lcccccc} & \mathrm{C} & \mathrm{H} & \mathrm{O} & \mathrm{N} & \mathrm{P} & \mathrm{Cu} \\ \text { Calculated } & 28 \cdot 98 & \mathbf{3 \cdot 6 2} & \mathbf{3 4 \cdot 4 4} & \mathbf{8 \cdot 2 2} & \mathbf{6 \cdot 0 7} & \mathbf{1 8 \cdot 6 6} \\ \text { Found (mean of duplicate } & 28 \cdot 63 & \mathbf{4 \cdot 1 8} & \mathbf{3 4 \cdot 6 8} & \mathbf{7 \cdot 8 4} & \mathbf{6 \cdot 0 5} & \mathbf{1 8 \cdot 6 2}\end{array}$

1 "Fuller's earth" proved to be a very effective adsorbent for colloidal copper sulphide but to retain not more than traces of the phosphorus-containing substances.

2 The analysis recorded in this and the following paper [1927] have been carried out either by Mr F. Flack of the Chemical Laboratory, or by Mr A. R. Colwell, of the Biochemical Laboratory; Cambridge or by "Fein Chemie," Tübingen. 
The purified substance represented just under $50 \%$ of the original organic phosphorus of the caseinogen digest. It was a light blue powder, insoluble in water but yielding solutions, when the copper was removed by hydrogen sulphide, which gave an intense red biuret reaction. The preparation of the free acid in the dry state is described below.

The two fractions $A$ and $D$, obtained during the purification of the crude material, were investigated in order to ascertain whether they contained other peptones in addition to that described above. The material $A$ had a ratio $\mathrm{N} / \mathrm{P}=2.6$ not far removed from that required by a substance containing 8 nitrogen atoms to 3 of phosphorus. Upon analysis, however, it was found to be a mixture of the peptone already described and copper phosphate. The fraction $D$ had a ratio $\mathrm{N} / \mathrm{P}=3 \cdot 18$, whilst that of the filtrate from the precipitation was $3 \cdot 4$, indicating that whatever impurity is present at this stage is there only in small quantity. All attempts to isolate from these fractions pure material having a higher ratio of nitrogen to phosphorus than that of the peptone described were without success. There appears to be some phosphorus-free material which follows the precipitation of the phosphoruscontaining peptone rather closely, and it seems possible that this may account for the variety of preparations with varying N/P ratios found by Posternak [1927].

Preparation and properties of the Free phosphopeptone.

$15 \mathrm{~g}$. pure copper salt were decomposed by hydrogen sulphide and the resulting solution concentrated over sulphuric acid in vacuo at room temperature. There resulted a highly viscous syrup which solidified to a "glass." All efforts to obtain crystalline material were unsuccessful. Upon dehydration with absolute alcohol and pulverisation the peptone was obtained as a white, slightly hygroscopic powder, dissolving readily in water to yield distinctly acid solutions. Difficulty was experienced in effecting the combustion of this material, but on analysis it gave the following figures, which agree fairly well with the formula $\mathrm{C}_{37} \mathrm{H}_{62} \mathrm{O}_{33} \mathrm{~N}_{9} \mathrm{P}_{3}$ calculated from the composition of the copper salt.

$\begin{array}{lcccc} & \mathrm{C} & \mathrm{H} & \mathrm{N} & \mathrm{P} \\ \text { Found } & \mathbf{3 7 \cdot 4 4} & \mathbf{5 \cdot 7 5} & \mathbf{1 0 \cdot 1 3} & \mathbf{7 . 0 5} \\ \text { Calculated } & \mathbf{3 5 \cdot 3 8} & \mathbf{5 . 1 4} & \mathbf{1 0 . 0 3} & \mathbf{7 \cdot 4 1}\end{array}$

The amino-nitrogen, determined by the method of Van Slyke, was 1/9 of the total nitrogen; after hydrolysis with hydrochloric acid, however, the amino-nitrogen became equal to the total nitrogen. One would infer therefore that the substance is a peptone consisting of 9 amino-acids in peptide linkage, all of which are acyclic mono-amino-acids. An aqueous solution gave the following colour and precipitation tests:

$\begin{array}{lll}\begin{array}{l}\text { Ninhydrin } \\ \text { Biuret }\end{array} & + & \begin{array}{l}\text { Picric acid } \\ \text { Phosphotungstic acid } \\ \text { Trichloroacetic acid }\end{array} \\ \begin{array}{l}\text { Glyoxylic } \\ \text { Millon }\end{array} & - & \text { Lead acetate } \\ \text { Xanthoproteic } & - & \text { Uranium acetate } \\ \begin{array}{l}\text { Sulphur test } \\ \text { Molisch }\end{array} & - & \text { Copper acetate } \\ \text { Muse) } & - & \text { Mercuric acetate } \\ \text { Silver nitrate + ammonia }\end{array}$

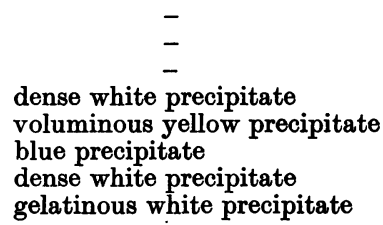


It was noted in addition that its aqueous solutions gave a deep, orange-red colour with diazobenzenesulphonic acid and sodium carbonate, which turned golden yellow on addition of hydrochloric acid but left no secondary colour whatever after reduction with zinc dust and hydrochloric acid and addition of ammonia. The diazo-reaction could not therefore be due to histidine, which gives a yellow secondary colour; it was afterwards traced to hydroxyglutamic acid which is present in the peptone and which, as observed by Dakin [1918], yields the primary colours described. An investigation of the products of hydrolysis is presented in the following paper.

The colour tests demonstrate the absence of tryptophan, tyrosine, aromatic substances, carbohydrates, cystine and histidine. The high oxygen content on the other hand suggests that hydroxyamino-acids may be present together with phosphoric acid.

As has been previously reported [Rimington and Kay, 1926], investigation showed that the substance was slowly hydrolysed by pancreatic juice, phosphoric acid being produced and the peptide linkages also attacked. Phosphatases on the other hand bring about the separation of the phosphorus as phosphoric acid within a few hours. Sodium hydroxide $(0 \cdot 25 \mathrm{~N})$ also liberates the whole of the phosphorus in inorganic form in 24 hours at $37^{\circ}$. Phosphopeptone is freely diffusible through collodion sacs.

Molecular weight. The determination of the molecular weight of the peptone could not be accomplished by any of the standard physico-chemical methods owing to its high degree of ionisation in solution, results being obtained which were very much too low. No better success was obtained when using the barium salt. The insolubility of the substance in camphor precludes employment of the method of Rast [1922]. From the analytical data, however, the ratio of amino-nitrogen to total nitrogen and from the action of bone phosphatase, which only removes $2 / 3$ of the total phosphorus as phosphoric acid, it seems that the formulation as given is most likely correct. In view of the ready diffusibility of the substance it is assumed that the molecular weight is that indicated by the empirical formula, namely, 1254 .

Optical activity. The peptone is strongly laevo-rotatory. The light used was the mercury green.

$\alpha$ in $2 \mathrm{dm}$. tube $-2 \cdot 659^{\circ}$.

Nitrogen determination on solution $165 \cdot 6 \mathrm{mg}$. per $100 \mathrm{cc}$.

$$
\begin{aligned}
{[\alpha]_{5461}^{15^{\circ}} } & =-80 \cdot 53^{\circ}, \\
M[\alpha] & =-1011 \cdot 53 .
\end{aligned}
$$

Basicity. The basicity was determined by titration, using $0 \cdot 1 \mathrm{~N}$ sodium hydroxide and thymolphthalein as indicator.

$0.1 \mathrm{~g}$. free acid required $6.9 \mathrm{cc}$. sodium hydroxide, whence basicity $=8 \cdot 7$.

The result is in good agreement with the analysis of the copper and barium salts which show the peptone to behave as a nine-basic acid. 
Brucine salt. It was hoped that the peptone might yield a crystalline salt with one of the alkaloids. To a strong aqueous solution of the free peptone, nine equivalents of brucine were added together with a little methyl alcohol to aid solution. The resulting solution was neutral in reaction. A slight excess of brucine was then added so that the mixture was alkaline to phenol red. No crystalline material separated, although within the course of a few hours an oil had precipitated. This was separated off, and allowed to stand for several months. It could not, however, be induced to crystallise but gave a glassy material which was ground, very thoroughly extracted with absolute alcohol, and the resulting powder dried in vacuo for analysis.

$\begin{array}{lcc} & \mathrm{N} & \mathrm{P} \\ \text { Found } & 8 \cdot 00 & 2 \cdot 10 \\ \text { Calc. for } \mathrm{C}_{244} \mathrm{H}_{286} \mathrm{O}_{64} \mathrm{~N}_{27} \mathrm{P}_{3} & 8 \cdot 02 & 1.98\end{array}$

It appears that the substance was the brucine salt of the peptone containing nine equivalents of brucine, with a molecular weight of approximately 4700 .

Barium salt. The barium salt was prepared by adding a saturated solution of baryta to a concentrated aqueous solution of the peptone until faintly alkaline and then pouring into alcohol. The insoluble barium salt was centrifuged off, washed repeatedly with absolute alcohol and dried in vacuo. It formed a fine white powder very soluble in water.

\begin{tabular}{|c|c|c|c|}
\hline \multicolumn{4}{|c|}{ Analysis $\left(\mathrm{C}_{37} \mathrm{H}_{53} \mathrm{O}_{\varepsilon 3} \mathrm{~N}_{9} \mathrm{P}_{3}\right) \mathrm{Ba}_{4 \cdot 5}$. } \\
\hline & $\mathbf{N}$ & $\mathbf{P}$ & $\mathrm{Ba}$ \\
\hline $\begin{array}{l}\text { Found } \\
\text { Calculated }\end{array}$ & $\begin{array}{l}6 \cdot 25 \\
6 \cdot 76\end{array}$ & $\begin{array}{l}4 \cdot 60 \\
4 \cdot 99\end{array}$ & $\begin{array}{l}32 \cdot 26 \\
33 \cdot 14\end{array}$ \\
\hline
\end{tabular}

\section{Discussion.}

Since the proof by Hammarsten [1877] that phosphorus is an integral constituent of the caseinogen molecule, research has repeatedly been directed to the discovery of the type of linkage by which this element is held in combination. By analogy with sulphur, it might be supposed that there exists a phosphorus-containing amino-acid; however, the ready production of orthophosphoric acid from caseinogen under the action of various mild reagents has led to the view that it is phosphoric acid which is built in some way into the nitrogenous complex.

Among the early attempts to separate phosphorus-containing material from caseinogen those of Salkowski [1901], Levene and Alsberg [1901] and Reh [1907] may be mentioned. All of these workers however used as their starting material peptic digests in which an enormous quantity of peptide material was present. In no case was any substance isolated in a pure form. Posternak [1927] has lately reported the isolation of a variety of phosphoruscontaining substances from tryptic digests of caseinogen. His experimental methods are not cited, nor are analytical data presented, so that it is difficult to form any opinion of his work. In the experience of the present writer material has several times been isolated which bore a close resemblance, from 
the point of view of elementary composition, to some of the preparations described by Posternak; in all cases however further work showed that these substances were still impure and that by suitable manipulation their components could be separated. In view of the above findings I find it difficult to believe that Posternak's preparations were homogeneous, and moreover I have been unable to confirm his statements regarding the structural units with which phosphoric acid is associated (see following paper). The alternative remains however, that the methods employed by him may have been so different from mine as to lead to dissimilar products. Of this, for the reasons stated above, I am unable to judge.

The phosphorus-containing complex present in tryptic digests of caseinogen appears to be largely, if not entirely, a phosphorus-containing peptone in which the phosphorus is present as phosphoric acid united by ester linkages to some or other of the amino-acids. The yield in which this purified peptone may be isolated corresponds to about $50 \%$ of the original organic phosphorus of the digest. Although not entirely trypsin-stable, its peptide linkages are comparatively resistant to this enzyme; the phosphorus is also liberated with great slowness by trypsin. Phosphatases, on the other hand [Rimington and Kay, 1926], bring about a very rapid liberation of the phosphorus as phosphoric acid.

\section{Summary.}

1. A phosphorus-containing peptone, $\mathrm{C}_{37} \mathrm{H}_{62} \mathrm{O}_{33} \mathrm{~N}_{9} \mathrm{P}_{3}$, has been isolated from tryptic digests of caseinogen in a yield corresponding to $50 \%$ of the organic phosphorus of the digest.

2. It is a strongly acidic substance forming well-defined copper and barium salts each containing nine equivalents of the metal. It titrates as a nine-basic acid. A brucine salt has also been obtained. The free acid has $[\alpha]_{5461}^{15^{\circ}}=-80 \cdot 53^{\circ}$.

3. The substance, which has been designated "phosphopeptone," contains 1/9 of its nitrogen in the form of amino-nitrogen. After hydrolysis the ratio amino-nitrogen/total nitrogen becomes unity.

4. Colour tests indicate the absence of the usual amino-acids, the biuret and ninhydrin reactions are however positive. A primary colour reaction is also given with diazobenzenesulphonic acid, but there is no secondary colour after reduction.

5. The peptide linkages of phosphopeptone are slowly attacked by trypsin, which also brings about the slow liberation of the phosphorus as phosphoric acid.

In conclusion I wish to express my thanks to Sir F. G. Hopkins for the interest he has taken in this work. My best thanks are also due to Dr H. D. Kay for much valuable criticism and many helpful suggestions. 


\section{REFERENCES.}

Biffi (1898). Virchow's Arch. 152, 130.

Dakin (1918). Biochem. J. 12, 290.

Hammarsten (1877). Zur Kenntn. d. Caseins, etc. (Upsala).

Levene and Alsberg (1901). Z. physiol. Chem. 31, 543.

Plimmer and Bayliss (1906). J. Physiol. 33, 439.

Posternak (1927). Compt. Rend. Acad. Sci. 184, 306; Biochem. J. 21, 289.

Rast (1922). Ber. deutsch. chem. Ges. 55, 1051.

Reh (1907). Hofmeister's Beitr. 11, 1.

Rimington (1927, 1). Biochem. J. 21, 204.

(1927, 2). Biochem. J. 21, 272.

(1927, 3). Biochem. J. 21, 1187.

Rimington and Kay (1925). Chem. Ind. 44, 256.

(1926). Biochem. J. 20, 777.

Salkowski (1901). Z. physiol. Chem. 32, 245.

Society of Chemical Industry, Basle (1923). Swiss patent, No. 104336. 